Article

\title{
Fast Frequency Support from Hybrid Wind Power Plants Using Supercapacitors
}

\author{
Qian Long ${ }^{1, *,+} \mathbb{D}$, Aivaras Celna ${ }^{2, \dagger}$, Kaushik Das ${ }^{1, *(\mathbb{D})}$ and Poul Sørensen ${ }^{1}$ (D) \\ 1 Department of Wind Energy, Technical University of Denmark, 4000 Roskilde, Denmark; posq@dtu.dk \\ 2 Ørsted A/S, 2820 Gentofte, Denmark; aivce@orsted.dk \\ * Correspondence: qialo@dtu.dk (Q.L.); kdas@dtu.dk (K.D.) \\ + These authors contributed equally to this work.
}

check for updates

Citation: Long, Q.; Celna, A.; Das, K.; Sørensen, P. Fast Frequency Support from Hybrid Wind Power Plants Using Supercapacitors. Energies 2021, 14, 3495. https://doi.org/10.3390/ en14123495

Academic Editor: Teuvo Suntio

Received: 11 May 2021

Accepted: 7 June 2021

Published: 12 June 2021

Publisher's Note: MDPI stays neutra with regard to jurisdictional claims in published maps and institutional affiliations.

Copyright: (c) 2021 by the authors. Licensee MDPI, Basel, Switzerland. This article is an open access article distributed under the terms and conditions of the Creative Commons Attribution (CC BY) license (https:// creativecommons.org/licenses/by/ $4.0 /)$.
Abstract: The concept of hybrid wind power plants (HWPPs) that consist of wind, solar and batteries has received a lot of attention, since HWPPs provide a number of advantages thanks to the complementary nature of wind and solar energy and the flexibility of batteries. Nevertheless, converter-based technologies, as interfaces of HWPPs to the utility grid, contribute to the reduction of total system inertia, making the system more volatile and creating additional threats to frequency stability. To address these operational challenges, the capability of supercapacitors (SCs) to provide fast frequency reserve (FFR) is explored in this paper to enhance the frequency response of the HWPP. Two topologies for integrating SCs into the HWPP are proposed: (1) connecting SC to the DC link of wind turbine (WT) via a DC-DC converter interface, (2) directly connecting SC to the DC link of WT without converter interface. Frequency controllers at the asset level are proposed for these two topologies accordingly. The idea of the proposed frequency controller is to provide frequency response by varying SC voltage in proportion to frequency deviation, namely droop-based FFR. A practical SC sizing method for FFR provision is also discussed. The simulation results have shown, that in the case of frequency event, the proposed frequency controllers for SCs in both topologies positively contribute to the frequency of the system by reducing the rate of change of frequency by at least $5 \%$ and improving frequency nadir by at least $10 \%$, compared to the case where the SC has no contribution to FFR. However, the capacitor size requirement for directly connected SC is more demanding in order to achieve the same level of improvement. The performance of frequency support has been highly related to total system inertia and control parameters. Therefore, any change to the severity of frequency events or control parameters calls for the reevaluation of the capacitance.

Keywords: hybrid wind power plants; system inertia; frequency stability; supercapacitors; fast frequency reserve; frequency controller

\section{Introduction}

To cope with environmental issues like climate change and global warming, a number of agreements in both national and international levels have been established, to highlight the necessity to reduce greenhouse gas emission and to promote the development of RESs [1,2]. Denmark, in the latest energy agreement [3], has committed to $50 \%$ of energy demand being from RES by 2030 and phase out all fossil fuels by 2050. As a consequence of increasing rates of variable RES in power systems, new challenges and obstacles have emerged. The replacement of conventional power plants with RES technologies reduces dispatchable capacity and introduces varying generation, thus making power systems more volatile. Besides, the majority of RES sources, like DFIG-based (IEC 61400-27-1 Type 3) and PMSG-based (IEC 61400-27-1 Type 4) WTs [4] and solar photovoltaics, are connected to the grid via the converter interface, having limited contribution to system inertia. The great reduction in total system inertia creates additional threats for power system stability and security. One of the main problems appearing in low-inertia power systems is that, even 
small disturbances, and events can cause large frequency excursions and high ROCOF values, which activate involuntary load shedding. This issue leads to frequency instability of the power system, and blackout eventually.

As FCR, which is the existing frequency service for handling power imbalances, will face challenges of meeting performance requirements of the system, a new frequency reserve-FFR is introduced into the FAS markets [5]. FFR can be an instrument to reduce high ROCOF and large frequency deviation in a situation with very low inertia. It is also stated in [5] that in the Nordic synchronous area, 100 MW of FFR should be able to cover 20 GWs of kinetic energy in a low-inertia system. However, how to enable fast frequency support from generation sources to mitigate the impact of imbalance in low-inertia systems remains to be answered.

Recently, there has been an interest in combining different RES technologies forming utility-scale HWPPs due to the enhanced controllability and utilization of electrical infrastructure [6]. A number of conducted research studies and the first built HWPPs (Kennedy Energy Park, Australia; Kavithal project, India) have shown the expanded capabilities of HWPPs to participate in the FAS market as the FCR provider. However, in order to capture revenues from FFR, the methodology for enabling utility-scale HWPPs to provide FFR services needs to be explored.

There are multiple publications on developing controllers to provide frequency response from WTs, where the kinetic energy from the rotor of WTs are transmitted to the grid [7-10]. However, the provision of such support can stress the mechanical components of the WTs [11], leading to the instability of the WT, as well as its reduced lifetime. SCs, as short-term energy storage devices with high power density, are suitable to provide fast frequency support. Several studies have developed controllers for SCs coupled with the DC link of the WTs to relieve the mechanical stress of the WTs. One common type of frequency control for SC-integrated WTs is synthetic inertia control, which enables the WTs to exhibit an inertia response similar to a synchronous machine in response to frequency disturbances [12-14]. Another type is fast frequency control based on droop control. Authors from [15] have proposed fast frequency control for the type 3 WT with the SC directly connected to the DC link. A fast frequency control strategy is presented in [16], designed for the type 4 WT with the SCs directly connected to the DC link. To date, few papers have discussed fast frequency controllers for SCs coupled with the DC link of WTs considering two topologies, that is, connected to DC link with or without a DC-DC converter, and provided a technical comparison between the two.

Fast frequency controllers for SC-integrated WTs are proposed in this work with the following contributions: (1) a new fast frequency control strategy is developed to enable FFR provision from the SCs that are connected to the DC link of the WTs via a DC/DC converter; (2) a performance comparison of FFR provision between two SC integration topologies is firstly provided with the SC sizing requirement taken into account; (3) the coordination of the fast frequency controllers with upper control level is also discussed, making them suitable for either standalone WPPs or HWPPs, while the latter is the focus of this paper; (4) the impact of control parameters on the performance of FFR provision is evaluated via sensitivity analysis in a low-inertia system.

The outline of the paper is as follows: the HWPP dynamic model and control are briefly presented in Section 2. In Section 3, two types of SC integration methods are discussed, followed by the detailed design of SC frequency controllers, and then size calculation for SC. Thereafter, the developed controls are validated in Section 4 in a 12-bus power system, using RMS simulation with relevant case studies. Finally, Section 5 summarizes the key findings of the paper and outlines possible paths for future work.

\section{HWPP Dynamic Modeling and Control}

\subsection{HWPP Model}

A model representation of the co-located HWPP is presented in Figure 1. The HWPP is connected to the grid using a 176 MVA $230 / 20 \mathrm{kV}$ transformer. Medium voltage $20 \mathrm{kV}$ 
terminal is used as PCC, where separate power plants-a WPP, a SPP and an ESS are connected. All the modeling and control for the HWPP has been done using power system analysis tool DIgSILENT PowerFactory [17].

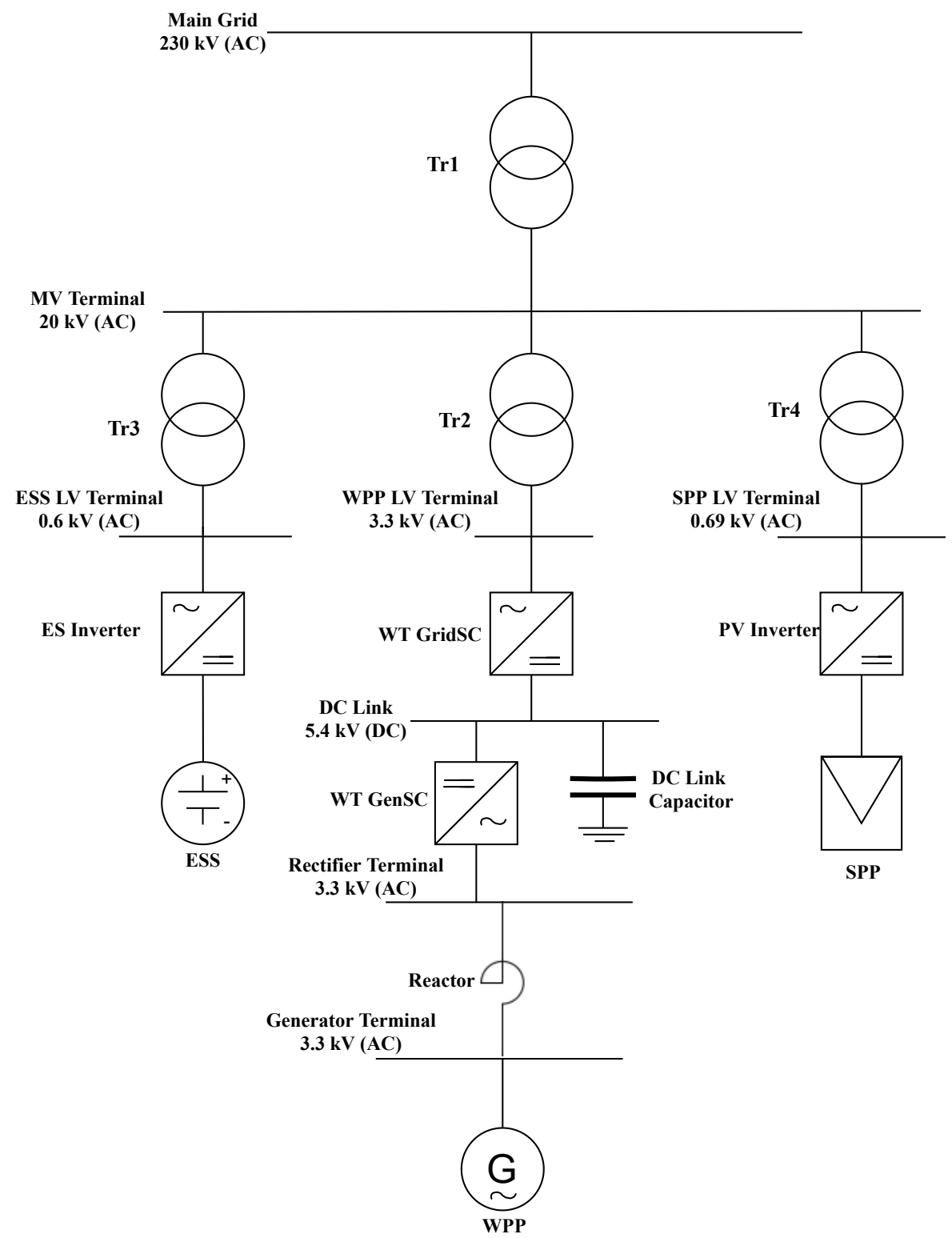

Figure 1. HWPP one line diagram.

WPP has been modelled by combining a synchronous generator and a back-to-back converter. The synchronous generator model represents 60 parallel-connected $2 \mathrm{MW}$ Type $4 \mathrm{WTs}$, which are connected to a generator side AC-DC converter via a shunt reactor. The generator side converter has a rated power of 150 MVA. It works in P-Vac control mode and is connected to the $5.4 \mathrm{kV}$ DC link capacitor. Another 150 MVA DC-AC grid side converter is responsible to deliver power from the DC link to the grid. It works in Vdc-Q mode and is connected to the PCC via a 132 MVA 3.3/20 kV transformer. SPP has been modelled using a built-in photovoltaic system element in PowerFactory. It consists of a current source and a DC-AC converter. The rated power of the SPP is $40 \mathrm{MW}$ and is connected to the PCC via a 45 MVA $0.69 / 20 \mathrm{kV}$ transformer. ESS has been modelled as a built-in battery storage element in PowerFactory, which contains a $10 \mathrm{MW} / 20 \mathrm{MWh}$ battery and a DC-AC converter with a rated capacity of 10 MVA. The ESS is connected through a 13 MVA $0.6 / 20 \mathrm{kV}$ transformer to the PCC. 


\subsection{HWPP Control}

An HWPP level controller is mainly responsible for controlling and managing individual power plants, and a simplified block diagram is provided in Figure 2. A total available power of the HWPP (neglecting ESS) is the sum of the available power of SPP and WPP, which are calculated using their MPPT blocks. Control functions block takes available power signals together with the control mode from system operators $(0,1$ or 2 representing no limitation, delta or balance control accordingly) [18] and adjusts power reference to the HWPP. The marked red area in Figure 2 represents the frequency controller of the HWPP. The FCR block has been implemented and it consists of both droop and ROCOF controllers. The FRR block is built for the implementation of frequency restoration reserve provision. Both of these frequency controllers generate power adjustment signals $d P_{F C R}$ and $d P_{F R R}$. These signals are summed up with initial power reference to generate power reference input $P_{r e f \_i n}$ to the PI controller, which gives the final power reference of the HWPP to the dispatch block. It should be remarked that, frequency controller for the SC integrated in the WT is implemented in the asset level other than the HWPP control level, therefore being suitable for scenarios with or without the HWPP control. However, to coordinate with FCR and FRR in the HWPP control, the FFR response needs to be estimated and added as a compensation signal $d \hat{P}_{F F R}$ to the PI control at the HWPP control level. Such a scheme ensures that the counteraction between the asset level and the HWPP control level is avoided. Furthermore, for simplicity, FCR and FRR control have been disabled in this paper when evaluating the performance of a newly implemented FFR.

Then, the dispatch block using signals of available power, state of charge of the battery and power reference allocates power setpoints for separate assets based on a set of rules (rule-based control). Generating priority is given to SPP, meaning that in the case of excess power, WPP is curtailed first. Furthermore, if ESS is not fully charged, it is used to store excessive power, reducing the loss of energy. In no limitation mode and delta control mode, ESS is not discharged, so that its power and energy are kept to provide frequency support. Only in balance control mode where power setpoints for the HWPP are higher than the total available power from RES, ESS is utilised for power generation.

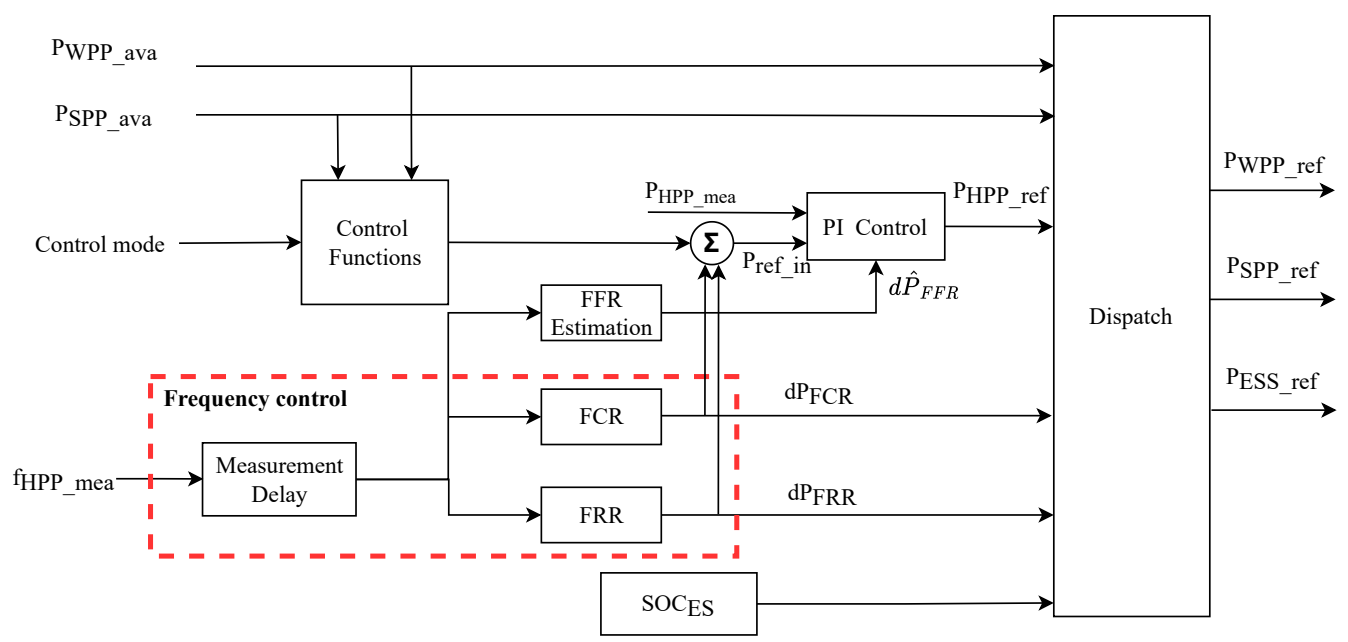

Figure 2. HWPP controller.

\section{Fast Frequency Response Using Supercapacitor}

\subsection{Supercapacitor Integration}

The model, where an SC has been added to the DC link of a WT in order to provide droop based FFR response, is shown in Figure 3. It is important to highlight that in such a configuration, the DC link is similar to a DC bus, where more than one power source is connected (WT and SC). SCs can be connected to the DC link via a DC-DC converter (Figure 3a) or directly connected to the DC link without converters (Figure 3b). The use of the DC-DC converter allows flexible control of SC with a wider range of voltage levels, 
but increases the capital costs due to the addition of the converters. On the other hand, the direct connection of SC requires lower cost, but the SC has to be of larger size to provide the required frequency support with the limited allowable voltage deviation at the DC link.

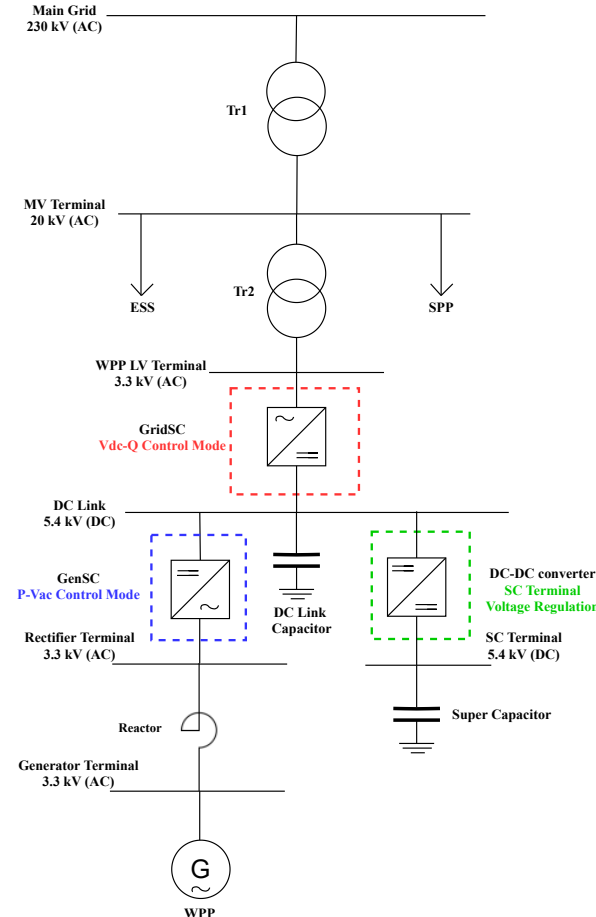

(a)

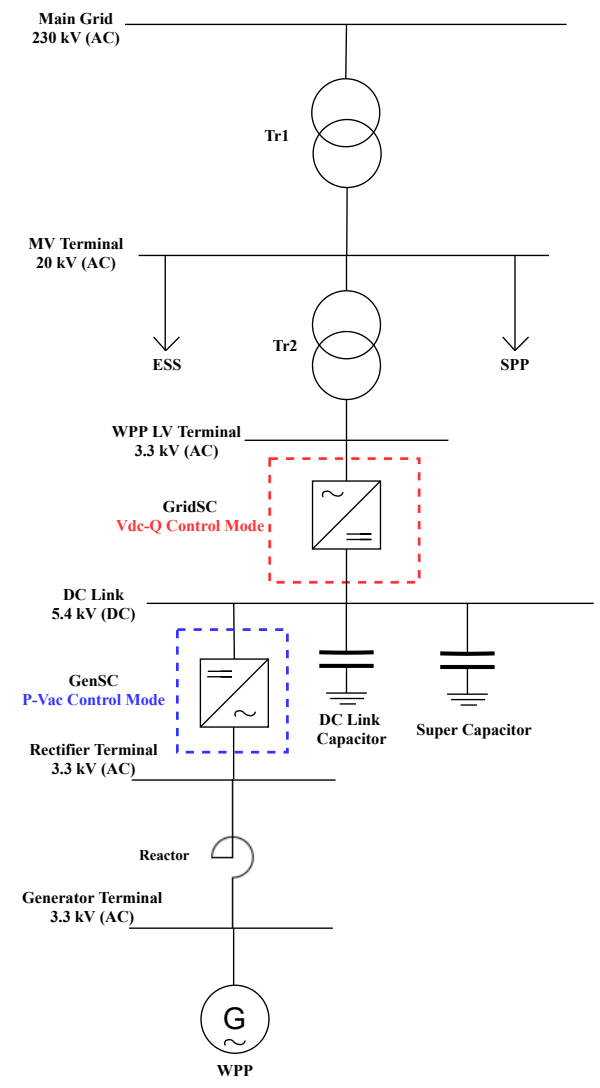

(b)

Figure 3. WT model with integration of SC. (a) WT model integrating SC via a DC-DC converter. (b) WT model directly integrating SC into DC link.

\subsection{Frequency Control Design}

The control diagram for WT generator side converter is presented in Figure 4a. The generator side converter works in P-Vac mode and is responsible for the control of active power flow from the WT to the DC link, as well as the regulation of the rectifier terminal voltage. P controller receives a power reference signal from the HWPP controller and compares it with power measurement in the rectifier terminal. Errors between the signals are fed into a PI controller, whose output is the d-axis current reference $i_{d}$. The voltage control of the generator is realised in a similar manner. The output of the voltage controller is the q-axis current reference $i_{q}$. Both power and voltage measurements as control feedback are passed through a low pass filter to eliminate high frequency noises. Finally, both d-axis and q-axis current reference signals go through a current limiter block, which assures that the converter is not forced to work above its nominal power, and then are sent to the converter with a built-in inner current controller. 


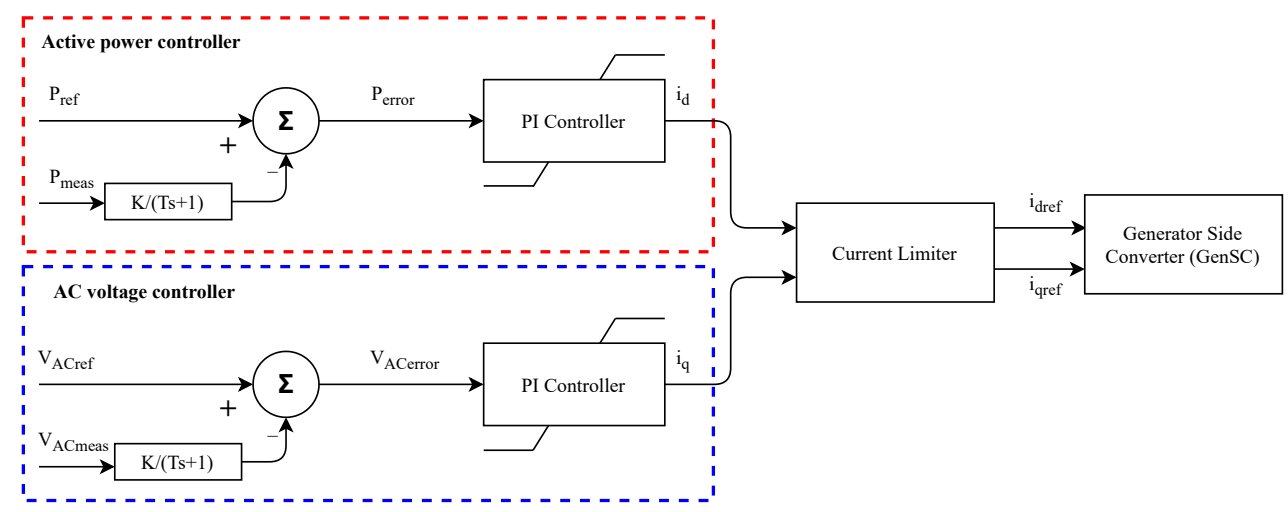

(a)

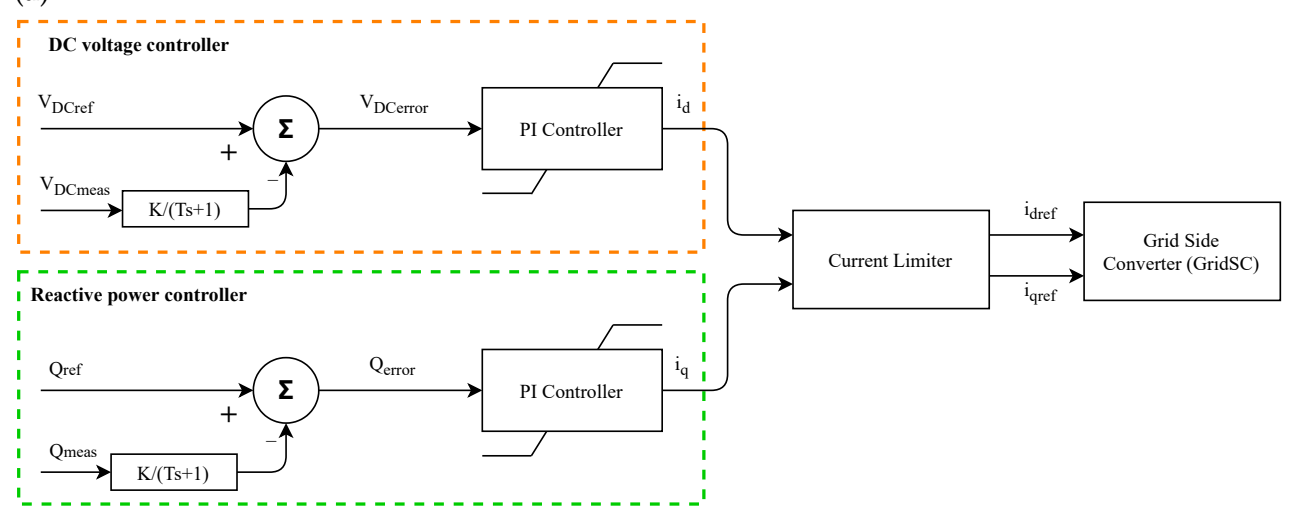

(b)

Figure 4. WT converter controllers. (a) WT generator side converter controller. (b) WT grid side converter controller.

The controller of the WT grid side converter is presented in Figure $4 \mathrm{~b}$. The grid side converter works in Vdc-Q mode. Since the generated power from both WT and SC affects the DC link voltage, the grid side converter regulates the DC link voltage by changing the $\mathrm{d}$-axis current reference and delivers the power to the main grid from either source. Besides this, the grid side converter also controls the reactive power of the AC terminal by adjusting its q-axis current references. By doing so, such control allows the grid side converter to provide voltage support to the grid. A similar current limiter specifies the lower and upper limits of the $\mathrm{d}$ and $\mathrm{q}$ axis current references, so that apparent power does not exceed the rated power capacity of the grid-side converter.

SC built in the DC link of the WT is supposed to provide droop based FFR. Given the control for WT, two additional frequency control designs are proposed to accommodate two SC integration methods; that is, with or without a DC-DC converter, respectively. Considering that $\mathrm{SC}$ is connected into the DC link with the converter, the DC-DC converter is responsible to control the current output of the SC. The converter takes as the input the signal $\alpha$, which corresponds to the ratio of the voltages on the controlled side and uncontrolled side. The value of $\alpha$ is calculated as follows:

$$
\alpha=\frac{V_{S C r e f}}{V_{D C \text { meas }}}=\frac{V_{S C n}-\Delta V_{S C}}{V_{D C m e a s}}
$$

where $V_{S C r e f}$-voltage reference of the SC [kV], $V_{S C n}$-SC nominal voltage [kV], $\Delta V_{S C}$ corrective voltage signal $[\mathrm{kV}], V_{D C \text { meas }}-$ measured $\mathrm{DC}$ voltage $[\mathrm{kV}]$. In this case, the controlled side is the SC terminal, while uncontrolled side is the DC link. In the steady state, when frequency is at nominal value $(\Delta f=0)$, voltage at the terminal of SC is constant and equal to the nominal DC link voltage. However, when frequency deviates from the nominal value, $V_{S C r e f}$ is regulated as described in Figure $5 b$, using a similar approach to droop control. It should be mentioned that as the SC power output depends on the derivative of 
the voltage (rate of change of voltage), the final frequency response seen from the grid is similar to inertia response. This means that SC power output eventually depends on the ROCOF. When frequency reaches steady state, regardless of what the steady-state value is, the power output from the SC will be equal to 0 .

In such topology where SC is connected directly to the DC link, the DC link voltage is regulated by the grid side converter. By adjusting the DC link voltage reference, the charging or the discharging of the SC is controlled. This method is similar to the one implemented in [15], with minor differences. As shown in Figure 5a, the DC link voltage reference for the grid side converter is determined by $V_{S C r e f}$ :

$$
V_{D C r e f}=V_{S C r e f}
$$

where $V_{D C r e f}-D C$ link voltage reference [kV]. However, extra attention should be paid to this connection topology in terms of design consideration. The range in which the DC link voltage varies is limited by the inequality as follows:

$$
V_{D C r e f}>V_{D C \text { min }}>\sqrt{2} V_{A C n(l-l)}
$$

where $V_{D C \text { min }}$-minimum DC voltage [kV], $V_{A C n(l-l)}$-peak line-to-line voltage at the AC side $[\mathrm{kV}]$. (3) guarantees that the grid side converter works with proper PWM. It also means that $\mathrm{SC}$ is not fully exploited if directly connected to the DC link compared to the SC with the DC-DC converter, where the SC can operate with much lower voltage (if not close to 0 ). To achieve the same response as the SC with a DC-DC converter, a much larger capacitor would be needed for SC directly connected to the DC link. Additionally, large capacitors in the DC link highly influence the closed loop converter dynamics and could create stability issues. Therefore, control parameters of both generated side converter and grid side converter need to be retuned for directly connected SC. In the end, which implementation method is preferred would depend on the costs of the SC and the DC-DC converter.

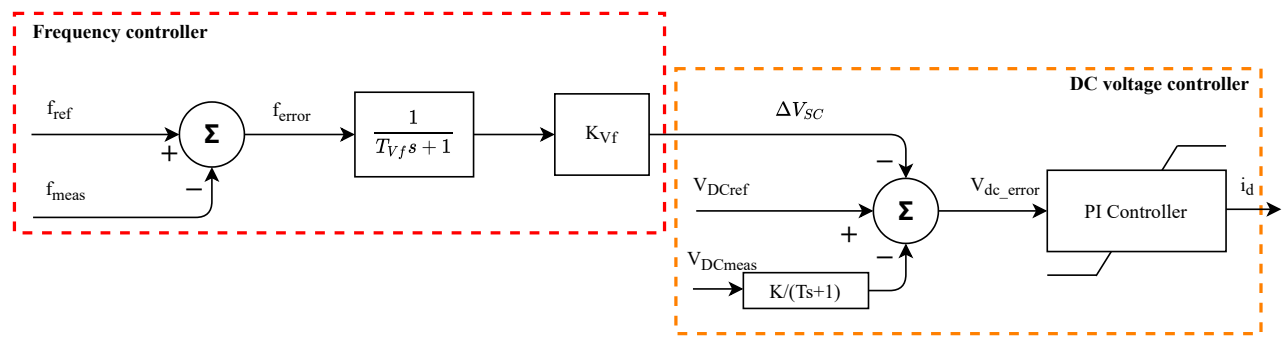

(a)

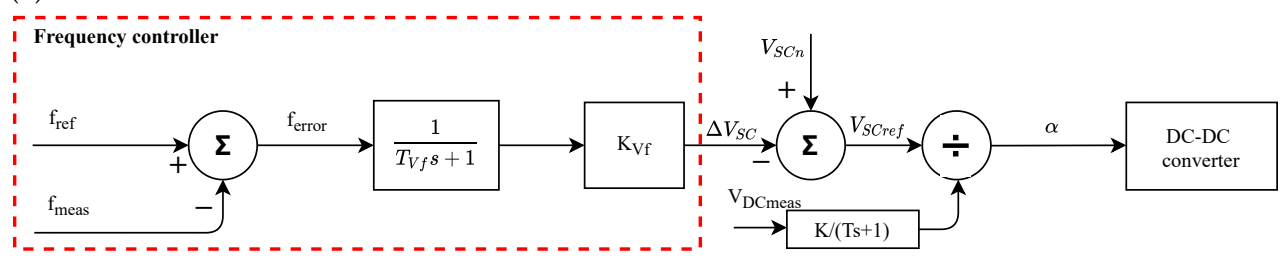

(b)

Figure 5. SC controllers. (a) Controller for directly-connected SC. (b) Controller for converterconnected SC.

\subsection{Size Calculation for Supercapacitor}

Considering ordinary droop control, frequency and power are linked by the following equation:

$$
R=\frac{\Delta f / f_{n}}{\Delta P / P_{n}}
$$

where $R$-droop coefficient [\%], $\Delta f$-frequency deviation from nominal frequency [Hz], $\Delta P$ - power deviation from power output at nominal frequency [MW], $P_{n}$-nominal power 
of generating technology [MW]. For simplicity, the negative sign is removed from the conventional definition of droop coefficient, and $\Delta f$ is redefined as $f_{n}-f_{\text {meas }}$ (positive for an under-nominal frequency, and negative otherwise). Droop coefficient represents the percentage of change in frequency at which the generating unit changes $100 \%$ of its power output $\left(\Delta f_{\max }=R f_{n}\right)$. In order to link droop coefficient with SC frequency control, maximum SC voltage deviation percentage has to be defined as:

$$
d_{\max }=\frac{\Delta V_{S C \max }}{V_{S C n}}
$$

where $d_{\max }$-maximum SC voltage deviation percentage [\%], $\Delta V_{S C \max }$-maximum allowable voltage deviation from SC nominal voltage for SC [kV]. The ratio between maximum voltage deviation and frequency deviation for a given droop coefficient result in the SC frequency control gain as follows:

$$
K_{V f}=\frac{\Delta V_{S C \max }}{\Delta f_{\max }}=\frac{d_{\max } V_{S C n}}{R f_{n}}
$$

where $K_{V f}$-frequency control gain [kV/Hz], $\Delta f_{\max }$-maximum frequency deviation [Hz]. It should be mentioned that frequency error $f_{\text {error }}$ is fed through a measurement filter with time constant $T_{V f}$ before being multiplied by the calculated gain $K_{V f}$.

To decide on the capacitance of the SC, the energy released by the SC during FFR, provision is calculated as follows:

$$
\Delta E=\frac{1}{2} C\left(V_{S C n}^{2}-V_{S C \min }^{2}\right)
$$

where $\Delta E$-energy released by SC $[M W \cdot s], C$-SC capacitance [F], $V_{S C \text { min }}$-minimum allowable SC voltage, equal to $V_{S C n}-\Delta V_{S C \max }[\mathrm{kV}]$. $V_{S C \min }$ can be close to zero for SCs connected to DC link via a DC-DC converter, or otherwise should fulfil (3) for directlyconnected SCs. Based on the definition of droop coefficient (4), the power generated by the droop based FFR is shown as follows:

$$
\Delta P=\frac{\Delta f / f_{n}}{R / P_{n}}
$$

where $\Delta P$-power output from SC [MW]. In order for the SC to fulfil the droop-based FFR requirement, the energy released by the SC should fulfil:

$$
\frac{1}{2} \Delta P \times \Delta T \leq \Delta E \leq \Delta P \times \Delta T
$$

where $\Delta T$-support duration [s]. The left-hand side of the inequalities (9) assumes a triangular shape for the FFR response with the magnitude $\Delta P$ and the duration $\Delta T$, while the right-hand side of the inequalities (9) assumes a rectangular shape for the FFR response with the same magnitude and duration. Therefore, the capacitance should be chosen to fulfil the following constraints by combining (7), (8) and (9):

$$
\frac{\Delta f P_{n} \Delta T}{R f_{n}\left(V_{S C n}^{2}-V_{S C \text { min }}^{2}\right)} \leq C \leq \frac{2 \Delta f P_{n} \Delta T}{R f_{n}\left(V_{S C n}^{2}-V_{S C \text { min }}^{2}\right)}
$$

It can be seen that the design value of the capacitance depends on the rated power of the main entity (in this case WT), support duration, droop coefficient and maximum voltage deviation. $\Delta f$ is a design parameter that is decided by the estimated frequency deviation during the frequency event. For example, if $\Delta f=1 \mathrm{~Hz}$, then it guarantees that as long as maximum frequency deviation is less than $1 \mathrm{~Hz}$ in the event, the SC will fulfil the 
frequency provision requirement without affecting the converter operation. $\Delta f$ can also be set directly to $\Delta f_{\max }$ and (10) can be simplified as:

$$
\frac{P_{n} \Delta T}{V_{S C n}^{2}-V_{S C \min }^{2}} \leq C \leq \frac{2 P_{n} \Delta T}{V_{S C n}^{2}-V_{S C \min }^{2}}
$$

however, (11) can lead to the overdimensioning of the capacitor for frequency events with smaller frequency deviations than $\Delta f_{\max }$. From (10) and (11), it is obvious that the capacitance required for the SC with a DC-DC converter is smaller, since a lower $V_{S C \min }$ is allowed compared to the SC with direct connection to the DC link.

\section{Results}

In this section, the designed HWPP model incorporating SCs is validated for the provision of FFR using a droop characteristic. The test system model is introduced at first. The responses from two types of SC integration strategies, that is, direct connection and connection via DC-DC converters, are then investigated and compared with each other in power system models with different inertia constants. Furthermore, the impact of different control parameters is inspected through sensitivity analysis. The base case in all the following case studies is the 'no control' case, where the proposed frequency control is disabled, such that no fast frequency response is provided by the SC.

It is worth noting, that in all of the simulations, HWPP is working in no power limitation mode, and it is assumed that wind speed is constant at $12 \mathrm{~m} / \mathrm{s}$ and solar irradiance at $1000 \mathrm{~W} / \mathrm{m}^{2}$, leading to the constant production of $120 \mathrm{MW}$ and $39.5 \mathrm{MW}$ for WPP and SPP, accordingly. In this mode, battery does not provide power, as it is assumed to be used for other services.

\subsection{Test System Model}

The main grid used in the PowerFactory simulation is a generic 12-bus system [19] developed for wind energy studies, shown in Figure 6. This system represents a UK power system consisting of 4 major areas. Area 1 and 2 have the majority of the generation comprising thermal units $\mathrm{G} 1$ and G2 and a hydro unit G4 with mainly industrial and rural loads (L01, L02, L06). Another thermal power plant (G3) is located in Area 3, where a heavy industrial load is connected (L03). Area 4 represents the southeast part of UK and has Bus 5, where the rural load L05 and the analysed HWPP is connected. Additionally, Bus 5 has two major connections with Bus 2 and Bus 4 via $400 \mathrm{~km}$ and $150 \mathrm{~km}$ lines, respectively. In all of the cases, the same event is simulated, where $250 \mathrm{MW}$ load L02 is increased by $50 \%(125 \mathrm{MW})$ at the simulation time $t=10 \mathrm{~s}$ if not stated differently in the following subsections. Changes applied to the 12-bus system and all the grid data are provided in the Appendix A.1. 


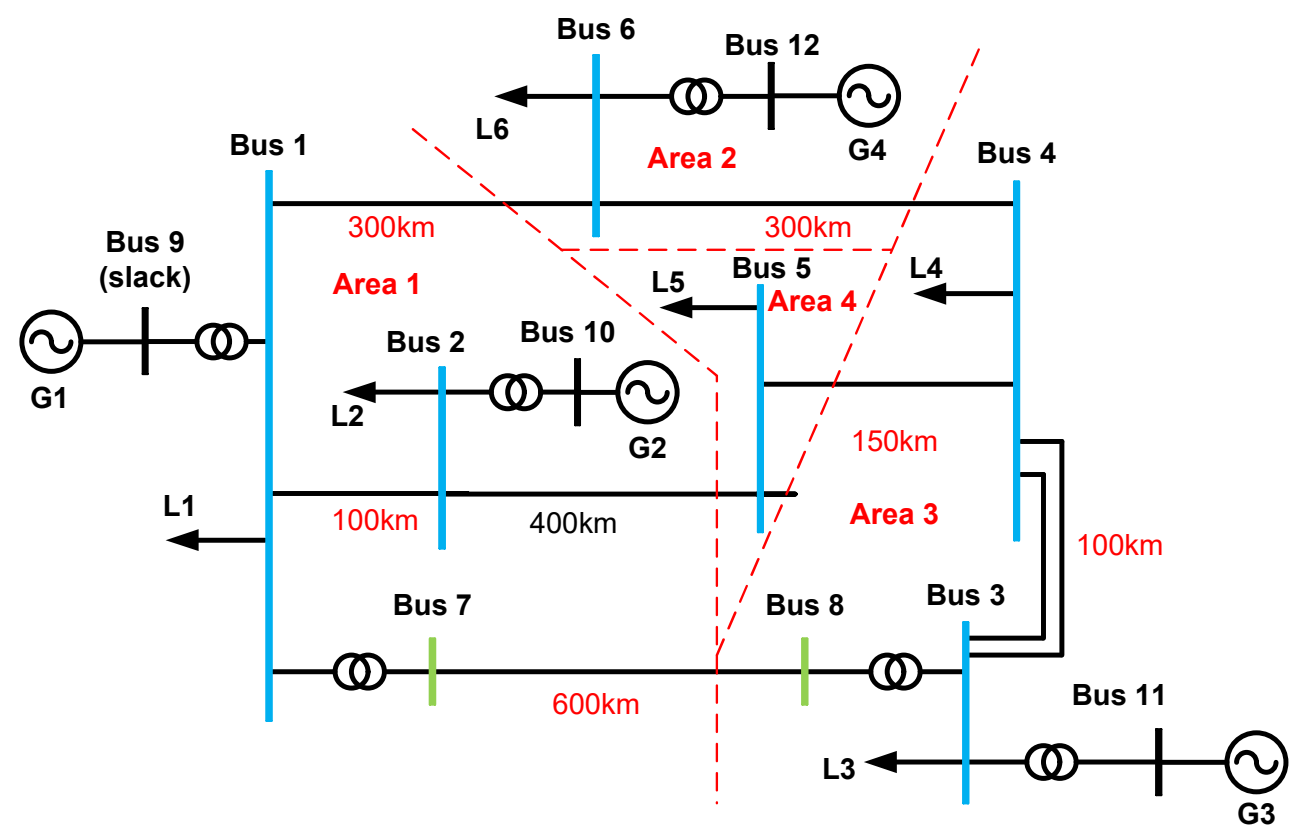

Figure 6. Generic 12-bus system topology [19].

\subsection{Validation of Droop-based FFR via Supercapacitor}

In this case, droop coefficient $R$ is chosen to be $5 \%$. Support duration $\Delta T$ is chosen to be $10 \mathrm{~s}$. The rated power of WPP $P_{n}$ is equal to $120 \mathrm{MW}$. The maximum frequency deviation $\Delta f$ during the event is $0.5 \mathrm{~Hz}$. For the directly connected SC, since the nominal voltage of the AC bus is $3.3 \mathrm{kV}$ (line to line), the minimum allowable voltage for SC is chosen to be $4.8 \mathrm{kV}(3.3 \times \sqrt{2}=4.7 \leq 4.8)$, considering reserving an extra voltage range. Therefore, the capacitor size for the directly-connected SC according to (10) results in:

$$
39.2 F \leq C \leq 78.4 F
$$

Similarly, for the SC with a DC-DC converter, the minimum allowable voltage for SC is chosen to be $1.1 \mathrm{kV}$ considering $80 \%$ maximum voltage deviation. The capacitor size for the converter-connected SC according to (10) results in:

$$
8.6 F \leq C \leq 17.2 F
$$

As a result, the capacitor sizes in this study are chosen to be $51.4 \mathrm{~F}$ for the directly connected SC and 11.3 F for the converter-connected SC, in order to meet (12) and (13). For the purpose of comparison, the capacitor sizes are selected such that similar frequency responses are achieved between two different topologies.

Simulation results for the directly connected SC are shown in Figure 7. It is seen that, compared to the base case, the SC with its frequency controller improves the frequency nadir from $49.53 \mathrm{~Hz}$ to $49.58 \mathrm{~Hz}$ and the ROCOF from $-0.14 \mathrm{~Hz} / \mathrm{s}$ to $-0.12 \mathrm{~Hz} / \mathrm{s}$ during the event, while it has no impact on steady state. The minimum SC voltage reaches $5.03 \mathrm{kV}$, which ensures that the grid side converter functions properly. Active power and current, the responses of which are inversely proportional to the frequency, rapidly increase to their peak values at $2.8 \mathrm{kA}$ and $14.7 \mathrm{MW}$, respectively, at $4 \mathrm{~s}$ after the event. Around $t=22 \mathrm{~s}, \mathrm{SC}$ starts to absorb power as the frequency overshoots slightly and then reaches a steady state. 

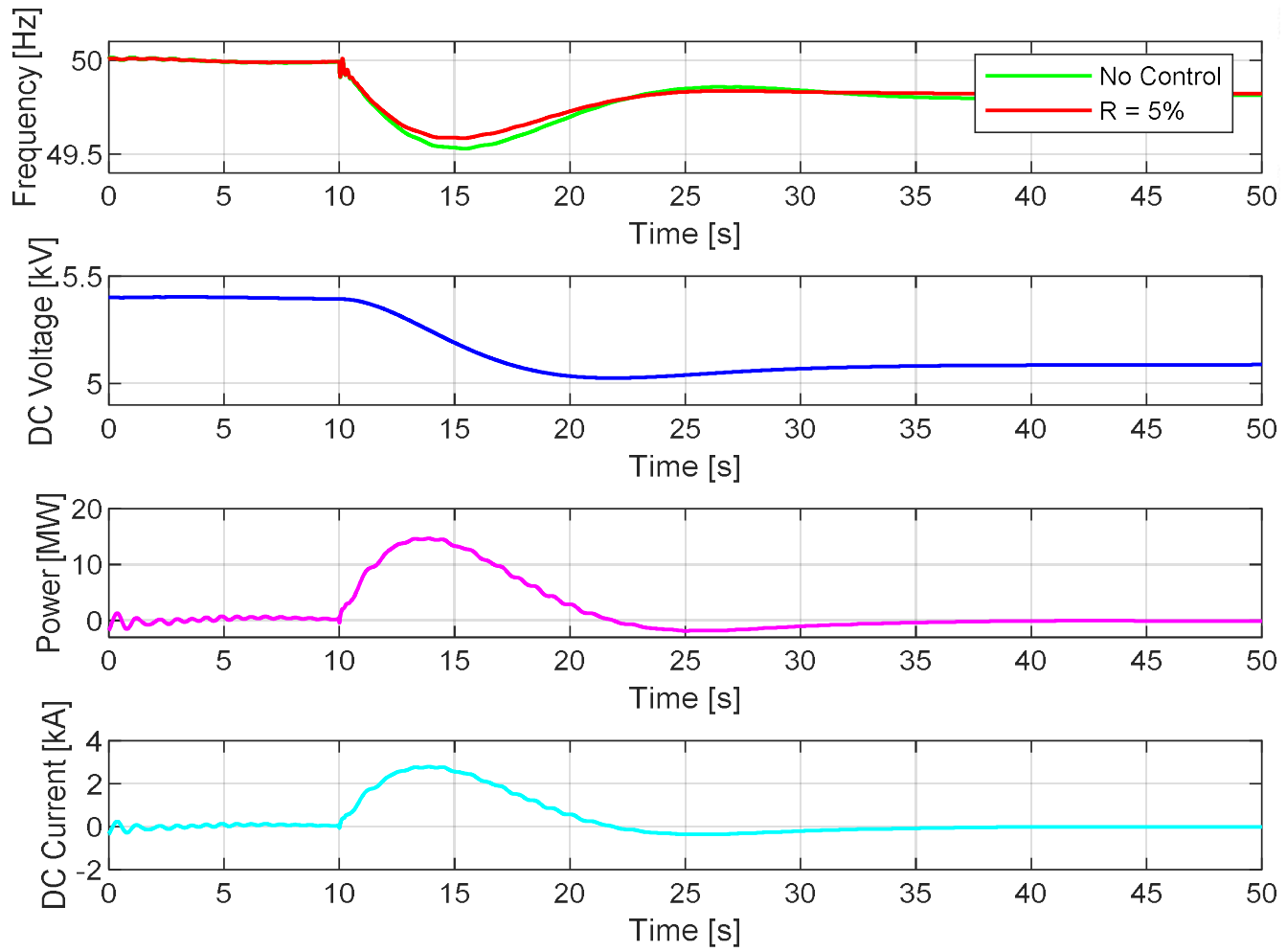

Figure 7. FFR provision from the directly-connected SC (from top to bottom: system frequency, SC terminal DC voltage, SC output DC power, SC output DC current).

Simulation results for the SC with a DC-DC converter are shown in Figure 8. Likewise, compared to the base case, the SC with its frequency controller also improves the frequency nadir from $49.53 \mathrm{~Hz}$ to $49.58 \mathrm{~Hz}$ and the ROCOF from $-0.14 \mathrm{~Hz} / \mathrm{s}$ to $-0.13 \mathrm{~Hz} / \mathrm{s}$ during the event, without any impact on steady state frequency. The minimum SC voltage reaches $3.64 \mathrm{kV}$, much less than the directly connected SC, because of its smaller capacitance. The responses of active power and current are similar to the directly connected SC, having their peak values at $2.8 \mathrm{kA}$ and $13.3 \mathrm{MW}$.

Based on the results above, two SC integration strategies have similar performance in terms of FFR provision. The selected capacitor sizes are sufficient for this particular frequency event with both SC topologies. However, the DC-DC converter allows a wider operating range of $\mathrm{SC}$ voltage and guarantees a similar frequency response with much smaller capacitance. The studied power system model has relatively high inertia constant $H=8.3 \mathrm{~s}$, thereby exhibiting small frequency deviation. Low-inertia systems and more aggressive frequency control settings, with which simulation results differ, are covered in the following subsection. 

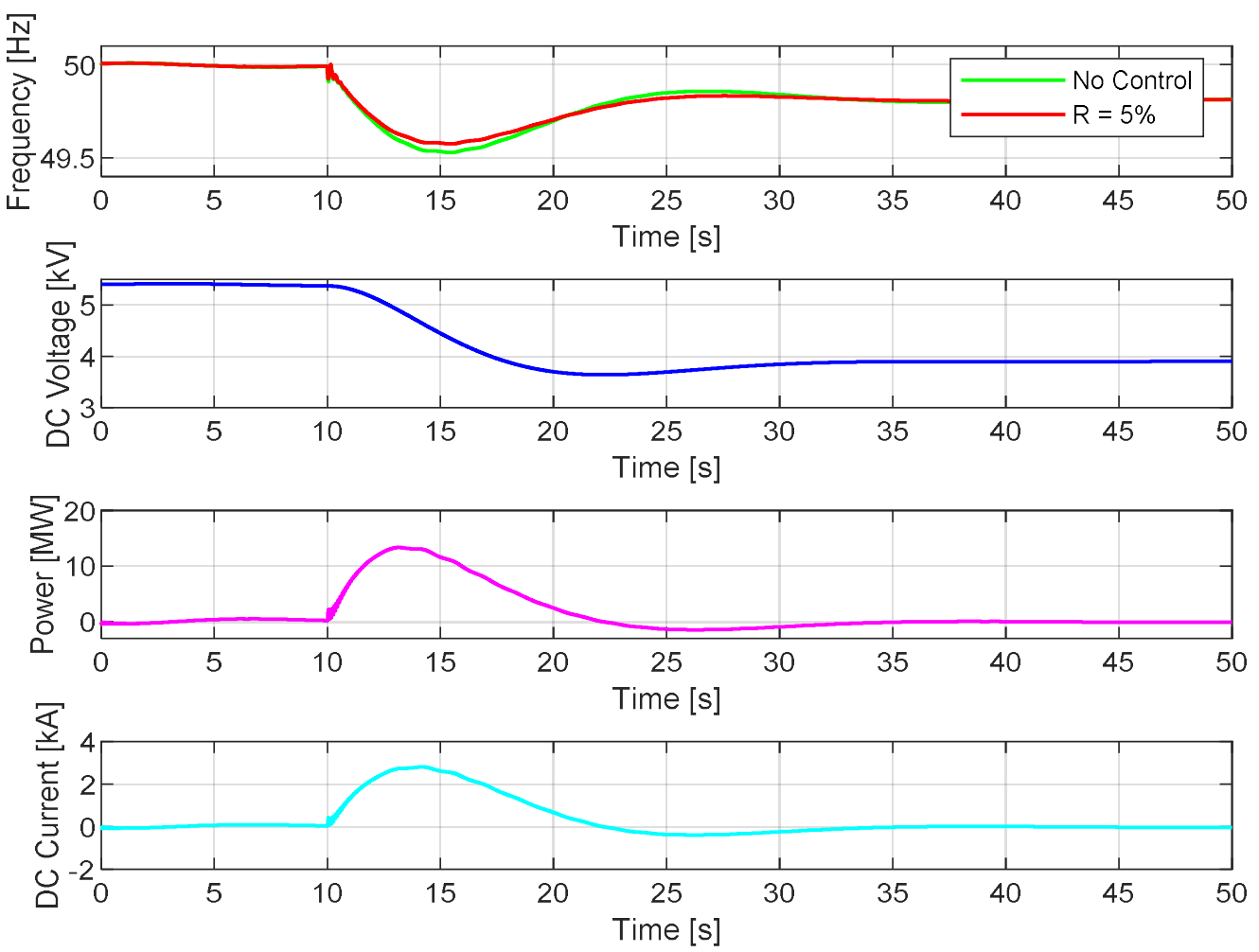

Figure 8. FFR provision from the converter-connected SC (from top to bottom: system frequency, SC terminal DC voltage, SC output DC power, SC output DC current).

\subsection{Low-Inertia Systems}

Droop coefficient $R$ is kept constant at $5 \%$ in this case study. The power system model used in the previous case study is modified here to exhibit the behavior of a low-inertia system. The modifications are listed as follows:

1. replace thermal plant G3 with a WPP having the same size, leading to inertia constant $H=7.1 \mathrm{~s}$.

2. replace both thermal plant G3 and hydro plant G4 with two WPPs having the same size, leading to inertia constant $H=5.7 \mathrm{~s}$.

Figure 9 shows simulation results of FFR provision from the directly connected SC in systems with different inertia constants and Table 1 summarizes the improvement of frequency nadir and ROCOF compared to the base case, as well as the SC states. Compared to $0.05 \mathrm{~Hz}$ frequency nadir improvement in the previous case with $H$ equal to $8.3 \mathrm{~s}$, there are further improvements on frequency nadir in systems with lower inertia $H=7.1 \mathrm{~s}$ and $H=5.7 \mathrm{~s}$, which are $0.09 \mathrm{~Hz}$ and $0.10 \mathrm{~Hz}$, respectively. The system with the lowest inertia experiences the largest frequency nadir and ROCOF improvement. Since the minimum SC voltages seen in all cases are larger than the minimum allowable voltage for $\mathrm{SC}$, the grid side converter works well with the proper DC voltage. However, it is worth pointing out that the minimum SC voltage seen in systems with $H=5.7 \mathrm{~s}$ already approaches a critical value, so there could be a malfunction in the grid side converter in a system with lower inertia. 

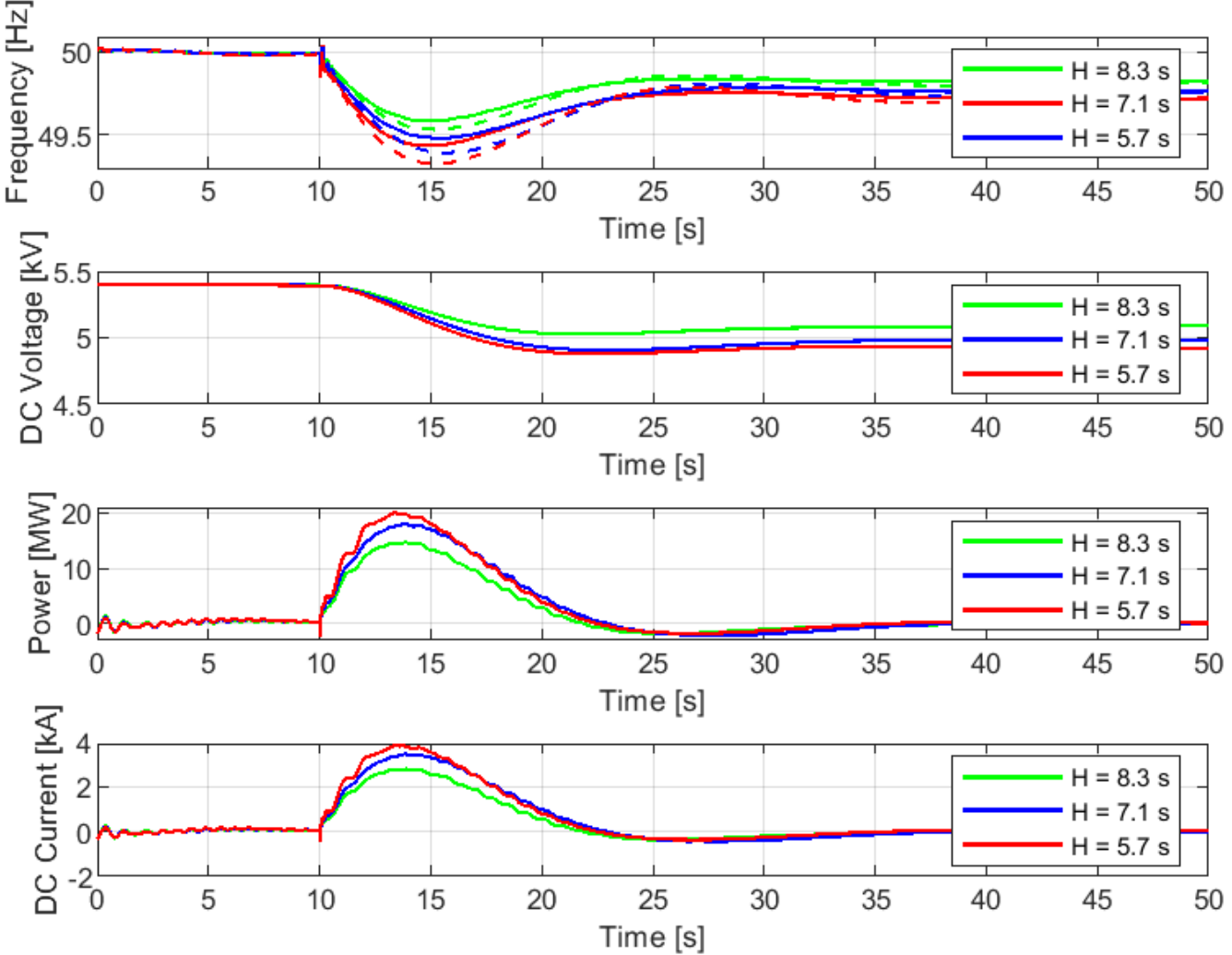

Figure 9. FFR provision from the directly connected SC in systems with different inertia constants (from top to bottom: system frequency (solid lines—cases with control, dash lines—cases without control), SC terminal DC voltage, SC output DC power, SC output DC current).

Table 1. Overview of simulation results of FFR provision from the directly connected SC in systems with different inertia constants.

\begin{tabular}{cccc}
\hline Parameters & $\boldsymbol{H}=\mathbf{8 . 3} \mathbf{~ s}$ & $\boldsymbol{H = 7 . 1 \mathbf { s }}$ & $\boldsymbol{H}=\mathbf{5 . 7} \mathbf{~ s}$ \\
\hline Frequency Nadir Improvement $(\mathrm{Hz})$ & 0.05 & 0.09 & 0.10 \\
ROCOF Improvement $(\mathrm{Hz} / \mathrm{s})$ & 0.02 & 0.02 & 0.04 \\
Minimum SC Voltage $(\mathrm{kV})$ & 5.03 & 4.91 & 4.88 \\
Maximum SC Power $(\mathrm{MW})$ & 14.66 & 18.05 & 19.98 \\
Maximum SC Current $(\mathrm{kA})$ & 2.79 & 3.46 & 3.82 \\
\hline
\end{tabular}

Figure 10 shows simulation results of FFR provision from the converter-connected SC in systems with different inertia constants, and Table 2 summarizes the improvement of frequency nadir and ROCOF compared to the base case as well as the SC states. Likewise, further improvements on frequency nadir are indicated in systems with lower inertia $H=7.1 \mathrm{~s}$ and $H=5.7 \mathrm{~s}$, compared to the previous case where inertia constant $H$ equals $8.3 \mathrm{~s}$. The system with the lowest inertia also experiences the largest frequency nadir and ROCOF improvement. Since the minimum allowable voltage for the converter-connected SC is much lower than the directly connected SC, the grid side converter works well with the selected capacitor size, providing similar frequency responses to the directly connected SC. 

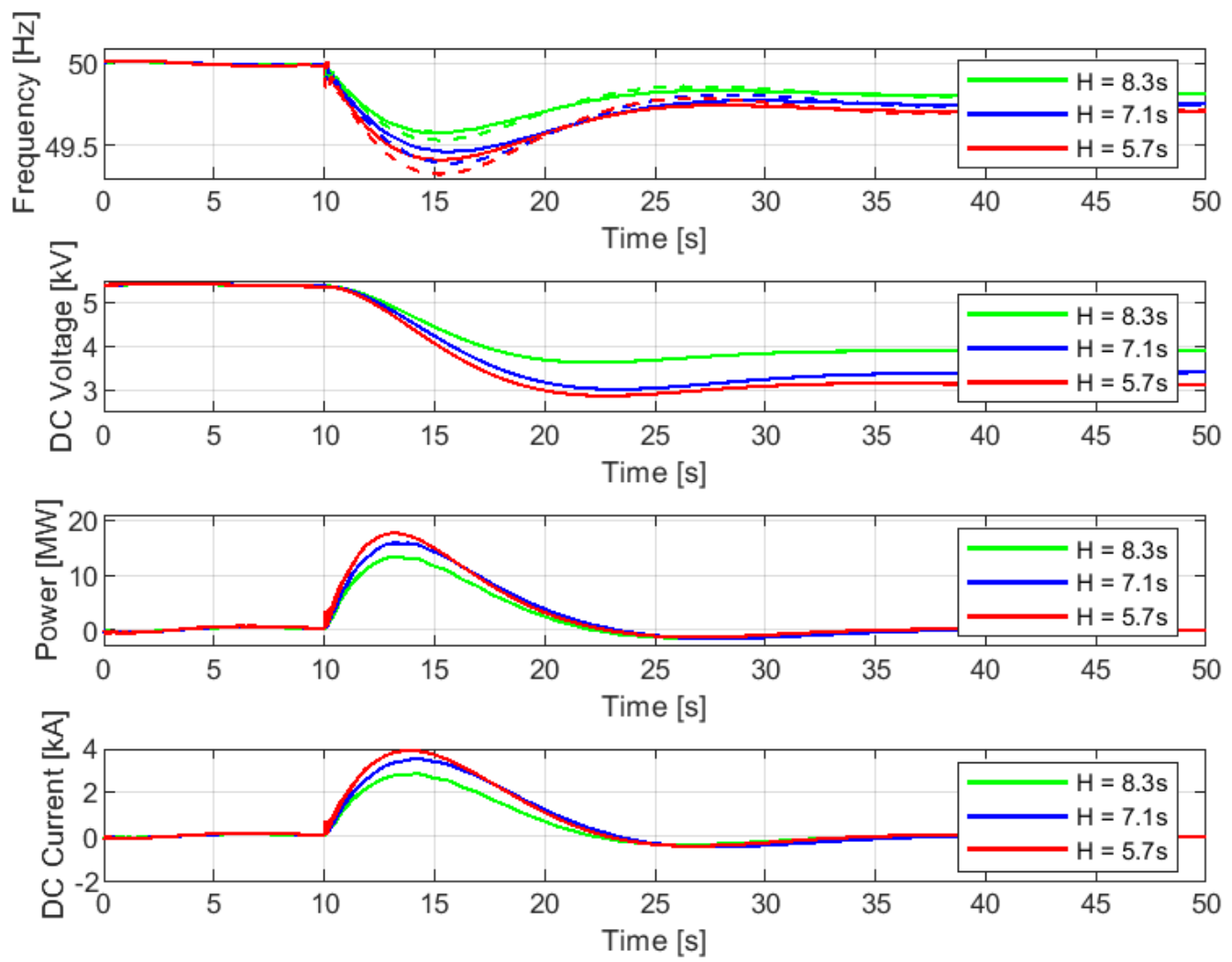

Figure 10. FFR provision from the converter-connected SC in systems with different inertia constants: (from top to bottom: system frequency (solid lines—cases with control, dash lines-cases without control), SC terminal DC voltage, SC output DC power, SC output DC current).

Table 2. Overview of simulation results of FFR provision from the converter-connected SC in systems with different inertia constants.

\begin{tabular}{cccc}
\hline Parameters & $\boldsymbol{H}=\mathbf{8 . 3} \mathbf{~ s}$ & $\boldsymbol{H}=\mathbf{7 . 1} \mathbf{~ s}$ & $\boldsymbol{H}=\mathbf{5 . 7} \mathbf{s}$ \\
\hline Frequency Nadir Improvement (Hz) & 0.05 & 0.08 & 0.09 \\
ROCOF Improvement $(\mathrm{Hz} / \mathrm{s})$ & 0.01 & 0.04 & 0.04 \\
Minimum SC Voltage (kV) & 3.64 & 3.03 & 2.88 \\
Maximum SC Power (MW) & 13.34 & 15.83 & 17.66 \\
Maximum SC Current (kA) & 2.80 & 3.48 & 3.85 \\
\hline
\end{tabular}

\subsection{Sensitivity Analysis}

\subsubsection{Changing Droop Coefficients}

In this case study, the influence of droop coefficients on the performance of the droop based FFR is analyzed for both the directly connected SC and the converter-connected SC in a low-inertia system $(H=5.7 \mathrm{~s})$. Droop coefficients are varied between $3 \%$ and $5 \%$ in one percent increments, while the rest of the parameters are kept the same $\left(P_{n}=120 \mathrm{MW}\right.$, $T_{V f}=10 \mathrm{~s}$ ). For the purpose of comparison, unlike the previous case studies, the same capacitance $C=51.4 F$ is used for both topologies.

Simulation results for sensitivity analysis of droop coefficients are shown in Figure 11, while a summary of main results is also provided in Table 3, with regard to the directlyconnected SC. As expected, lower droop coefficients indicate better frequency responses, where higher frequency nadir is obtained, along with lower ROCOF. It is because smaller droop coefficients represent a more aggressive frequency control action with a faster discharging of SC. As the rate of change of SC voltage increases with lower droop coefficients, SC power output increases as well, leading to higher voltage deviations at the SC terminal (voltage nadir of $4.55 \mathrm{kV}, 4.77 \mathrm{kV}$ and $4.88 \mathrm{kV}$ for droop coefficients $3 \%, 4 \%$ and $5 \%$ 
respectively). Notice that with $R=3 \%$, oscillation occurs in frequency, SC output power and output current at around $t=18 \mathrm{~s}$. The oscillation results from bad PMW of the grid side converter, which is caused by low SC voltage. This phenomenon is also aligned with the previous size calculation of the capacitor. Since the capacitance $C$ is determined based on $R=5 \%$, a selection process for the capacitance of the directly-connected SC based on (12) and (13) is called for, due to different droop coefficients.

Simulation results for a sensitivity analysis of droop coefficients is shown in Figure 12, while a summary of the main results is also provided in Table 4, with regard to the converterconnected SC. The same observations apply to frequency response, SC voltage, SC output power and output current. The performance of FFR provision is very similar to the directly connected SC. The main difference under this scenario is that no oscillation is observed for any droop coefficient thanks to the DC-DC converter, which allows a wider range of SC voltage and have only indirect effect on DC link voltage.

It could be concluded that lower droop coefficients further improve the performance of droop based FFR, including frequency nadir and average ROCOF, regardless of the SC integration methods. However, special attention needs to be paid to the selection of the directly connected capacitor if the proposed frequency control is redesigned with new droop coefficients, since the droop coefficient plays a role in capacitor size calculation.
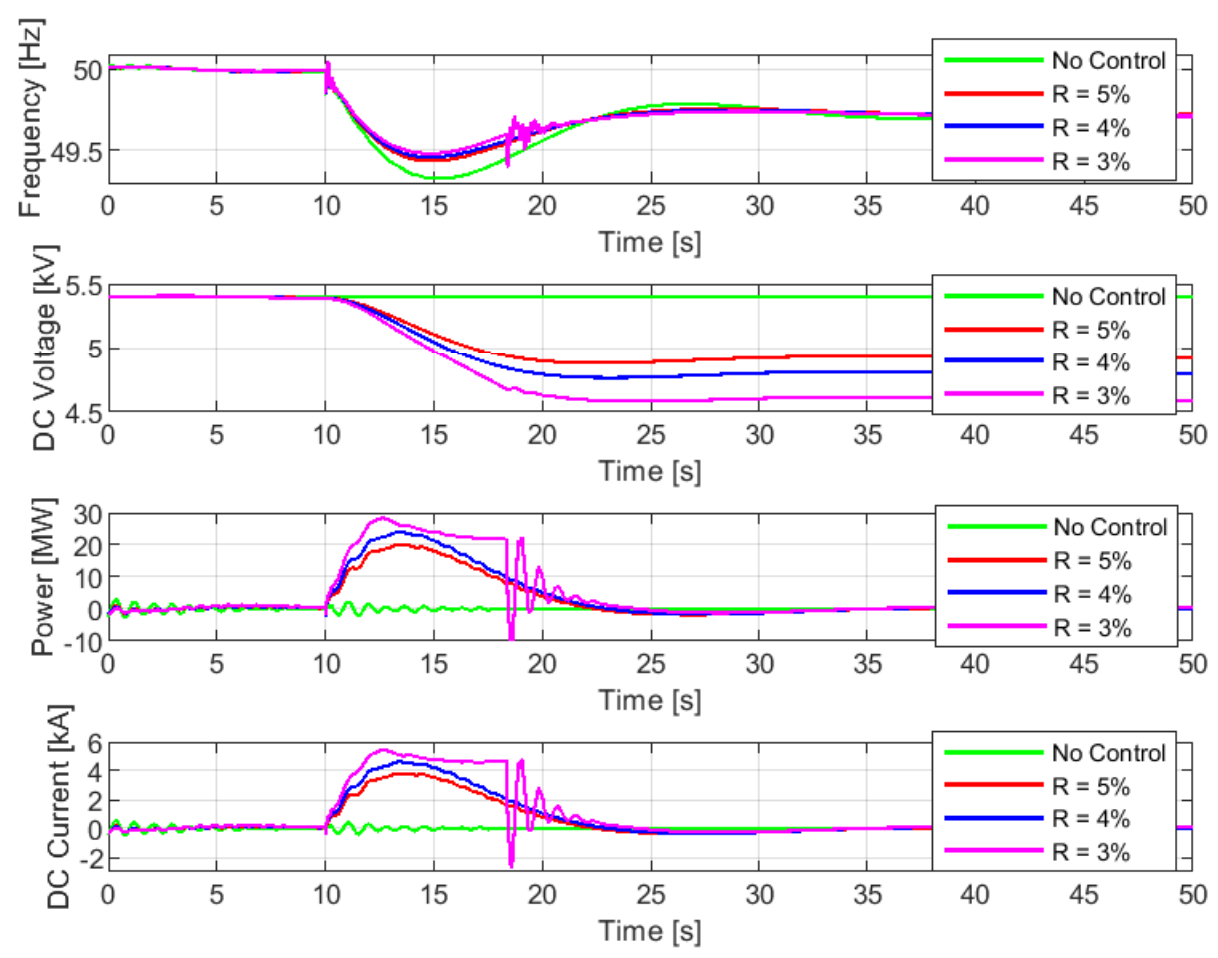

Figure 11. FFR provision from the directly connected SC with varying droop coefficients (from top to bottom: system frequency, SC terminal DC voltage, SC output DC power, SC output DC current).

Table 3. Overview of simulation results of FFR provision from the directly-connected SC in systems with varying droop coefficients.

\begin{tabular}{cccc}
\hline Parameters & $\boldsymbol{R}=\mathbf{3} \%$ & $\boldsymbol{R}=\mathbf{4 \%}$ & $\boldsymbol{R}=\mathbf{5} \%$ \\
\hline Frequency Nadir Improvement $(\mathrm{Hz})$ & 0.15 & 0.13 & 0.10 \\
ROCOF Improvement $(\mathrm{Hz} / \mathrm{s})$ & 0.06 & 0.05 & 0.04 \\
Minimum SC Voltage $(\mathrm{kV})$ & 4.55 & 4.77 & 4.88 \\
Maximum SC Power $(\mathrm{MW})$ & 28.30 & 23.97 & 19.98 \\
Maximum SC Current $(\mathrm{kA})$ & 5.43 & 4.62 & 3.82 \\
\hline
\end{tabular}



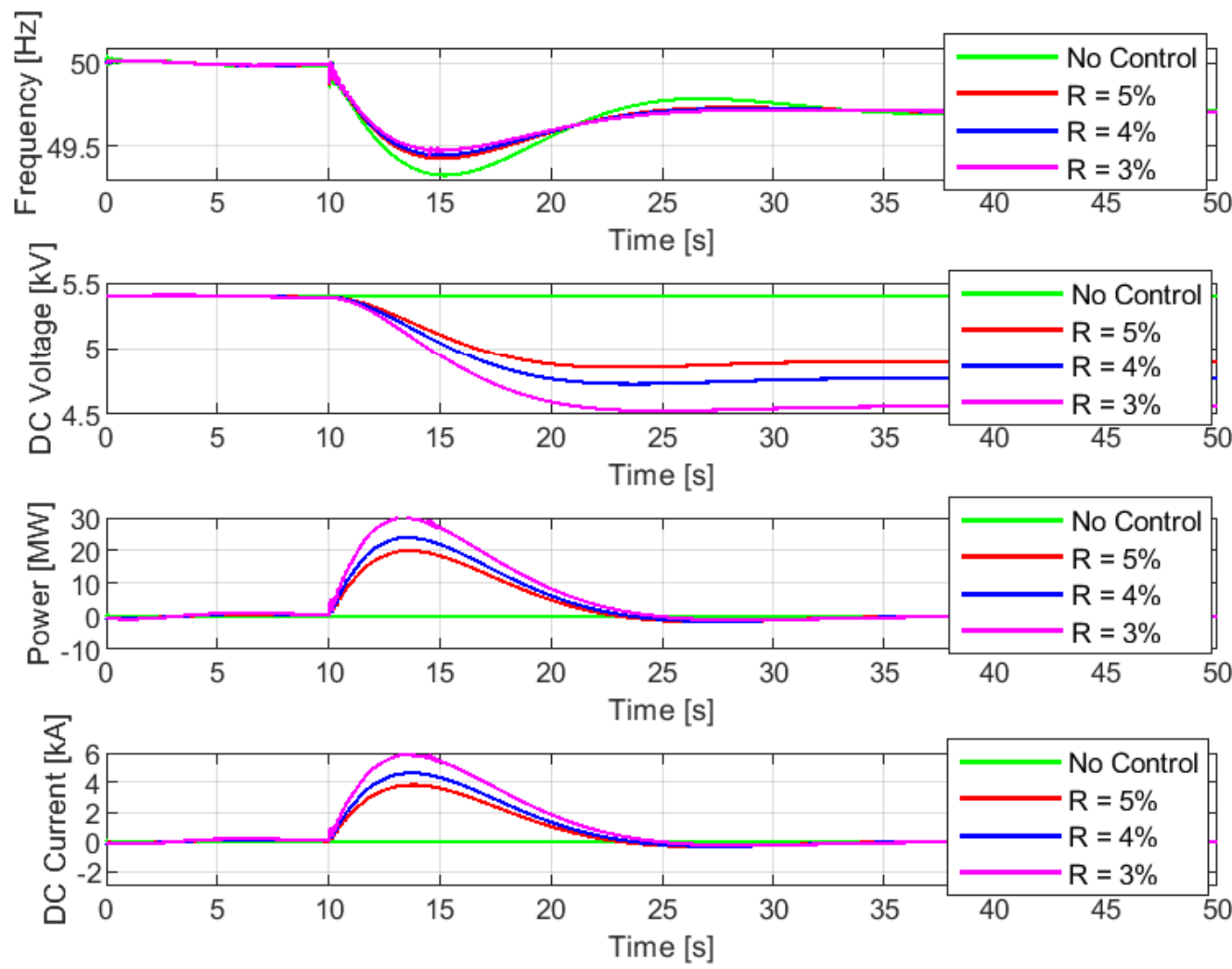

Figure 12. FFR provision from the converter-connected SC with varying droop coefficients (from top to bottom: system frequency, SC terminal DC voltage, SC output DC power, SC output DC current).

Table 4. Overview of simulation results of FFR provision from the converter-connected SC in systems with varying droop coefficients.

\begin{tabular}{cccc}
\hline Parameters & $\boldsymbol{R}=\mathbf{3} \%$ & $\boldsymbol{R}=\mathbf{4 \%}$ & $\boldsymbol{R}=\mathbf{5 \%}$ \\
\hline Frequency Nadir Improvement (Hz) & 0.13 & 0.11 & 0.10 \\
ROCOF Improvement (Hz/s) & 0.04 & 0.03 & 0.02 \\
Minimum SC Voltage (kV) & 4.52 & 4.73 & 4.85 \\
Maximum SC Power (MW) & 30.14 & 24.09 & 19.94 \\
Maximum SC Current (kA) & 5.87 & 4.66 & 3.83 \\
\hline
\end{tabular}

\subsubsection{Changing Time Constant}

In this case study, the influence of time constant of the low-pass filter $T_{V f}$ on the performance of the droop-based FFR is analyzed for both the directly-connected SC and the converter-connected SC in a low-inertia system $(H=5.7 \mathrm{~s})$. Time constants are varied from $5 \mathrm{~s}$ to $10 \mathrm{~s}, 15 \mathrm{~s}$ and $20 \mathrm{~s}$, while the rest of the parameters are kept the same $\left(P_{n}=120 \mathrm{MW}\right.$, $R=5 \%$ ). For similar purposes, the same capacitance $C=51.4 F$ is used for both topologies.

Simulation results are summarized in Figure 13 and Table 5 for the sensitivity analysis of the time constant considering the directly-connected SC. From Figure 13, it can be seen, that with higher time constants, SC voltage is regulated at a much slower pace, with higher nadir and smaller undershoot for the directly connected SC. The peak active power provided by the SC in the case of $T_{V f}=5 \mathrm{~s}$ is $28.16 \mathrm{MW}$, more than twice as high as 12.57 MW in the case of $T_{V f}=20 \mathrm{~s}$, although the capacitance is the same. Differences among cases are also reflected in the system frequency, where the highest frequency nadir and the lowest ROCOF are with $T_{V f}=5 \mathrm{~s}(49.48 \mathrm{~Hz}$ and $-0.16 \mathrm{~Hz} / \mathrm{s})$, and lowest frequency nadir and the highest ROCOF with $T_{V f}=20 \mathrm{~s}(49.39 \mathrm{~Hz}$ and $-0.20 \mathrm{~Hz} / \mathrm{s})$. It could be seen that the best case is with $T_{V f}=5 \mathrm{~s}$, as the smallest delay is introduced to frequency feedback by the low-pass filter, leading to the largest voltage deviation and the fastest control action 
from the SC. However, for the directly connected SC, a faster control action under the case of $T_{V f}=5 \mathrm{~s}$ comes at the expense of low DC voltage that imperils proper PWM, and causes oscillations on system frequency and SC output current at around $t=17 \mathrm{~s}$.
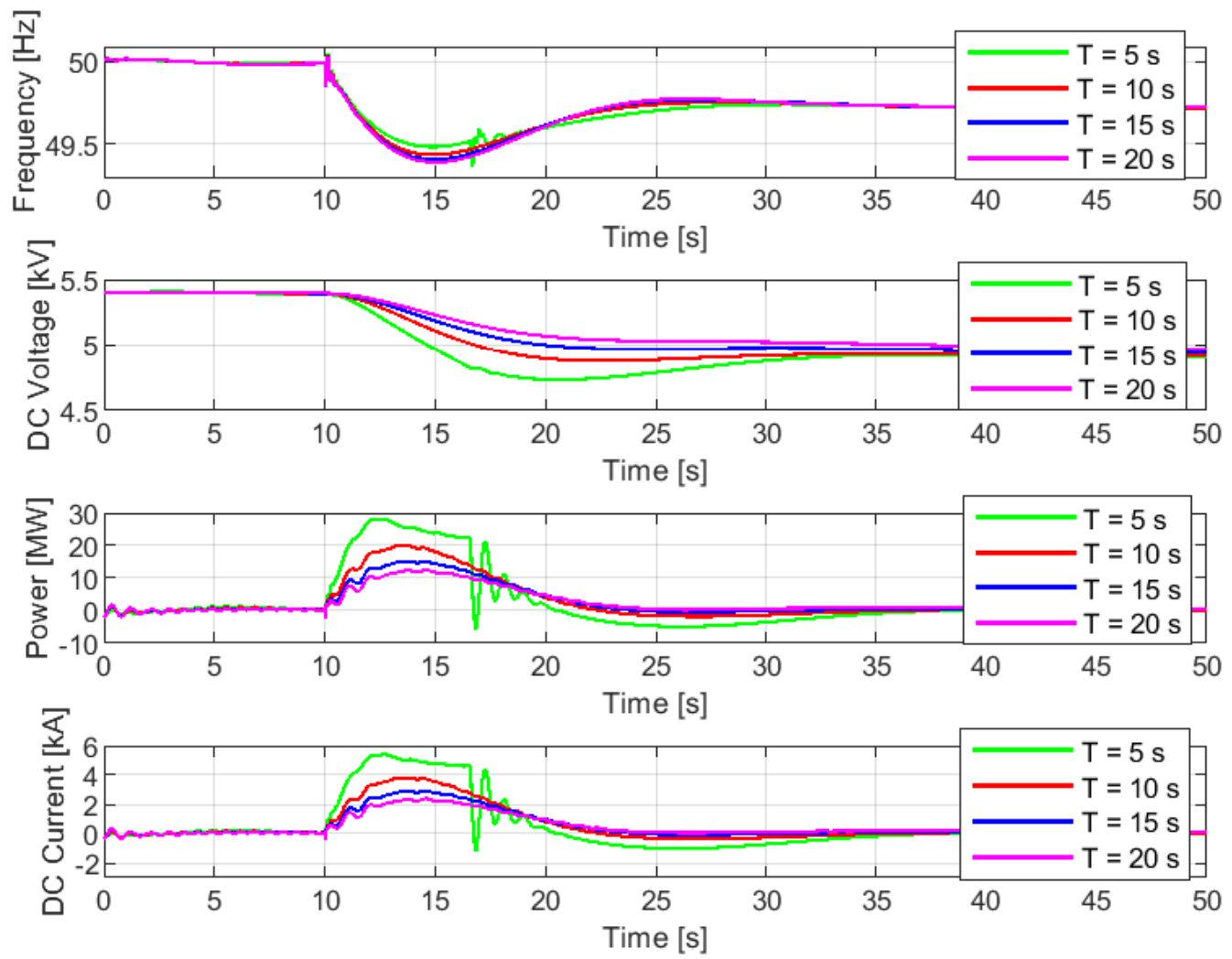

Figure 13. FFR provision from the directly connected SC with varying time constants (from top to bottom: system frequency, SC terminal DC voltage, SC output DC power, SC output DC current).

Table 5. Overview of simulation results of FFR provision from the directly connected SC in systems with varying time constants.

\begin{tabular}{ccccc}
\hline Parameters & $\boldsymbol{T}_{\boldsymbol{V} f}=\mathbf{5 ~ \mathbf { s }}$ & $\boldsymbol{T}_{\boldsymbol{V} f}=\mathbf{1 0} \mathbf{s}$ & $\boldsymbol{T}_{\boldsymbol{V} f}=\mathbf{1 5} \mathbf{s}$ & $\boldsymbol{T}_{\boldsymbol{V} f}=\mathbf{2 0 ~ \mathbf { s }}$ \\
\hline Frequency Nadir Improvement (Hz) & 0.16 & 0.10 & 0.08 & 0.06 \\
ROCOF Improvement (Hz/s) & 0.06 & 0.04 & 0.03 & 0.02 \\
Minimum SC Voltage (kV) & 4.74 & 4.88 & 4.94 & 4.97 \\
Maximum SC Power (MW) & 28.16 & 19.98 & 15.22 & 12.57 \\
Maximum SC Current (kA) & 5.41 & 3.82 & 2.92 & 2.39 \\
\hline
\end{tabular}

Simulation results are summarized in Figure 14 and Table 6 for the sensitivity analysis of the time constant considering the converter-connected SC. Figure 14 shows that with the converter-connected SC, the impact of the time constant follows a similar pattern to the directly-connected SC, where smaller time constants contribute to better frequency response, larger SC voltage deviation and faster control action. The highest frequency nadir and the lowest ROCOF is with the case of $T_{V f}=5 \mathrm{~s}(49.47 \mathrm{~Hz}$ and $-0.17 \mathrm{~Hz} / \mathrm{s})$, and the lowest frequency nadir and the highest ROCOF with the case of $T_{V f}=20 \mathrm{~s}(49.39 \mathrm{~Hz}$ and $-0.19 \mathrm{~Hz} / \mathrm{s}$ ). The SC voltage nadir reaches $4.7 \mathrm{kV}$ in the case of $T_{V f}=5 \mathrm{~s}$, making it the lowest nadir among all the cases due to the fastest frequency feedback. The peak active power provided by the SC in the case of $T_{V f}=5 \mathrm{~s}$ is $29.58 \mathrm{MW}$, more than twice as high as 12.28 MW in the case of $T_{V f}=20 \mathrm{~s}$. Note that no oscillation is observed from simulation results with $T_{V f}=5 \mathrm{~s}$, thanks to the extra DC-DC converter. 

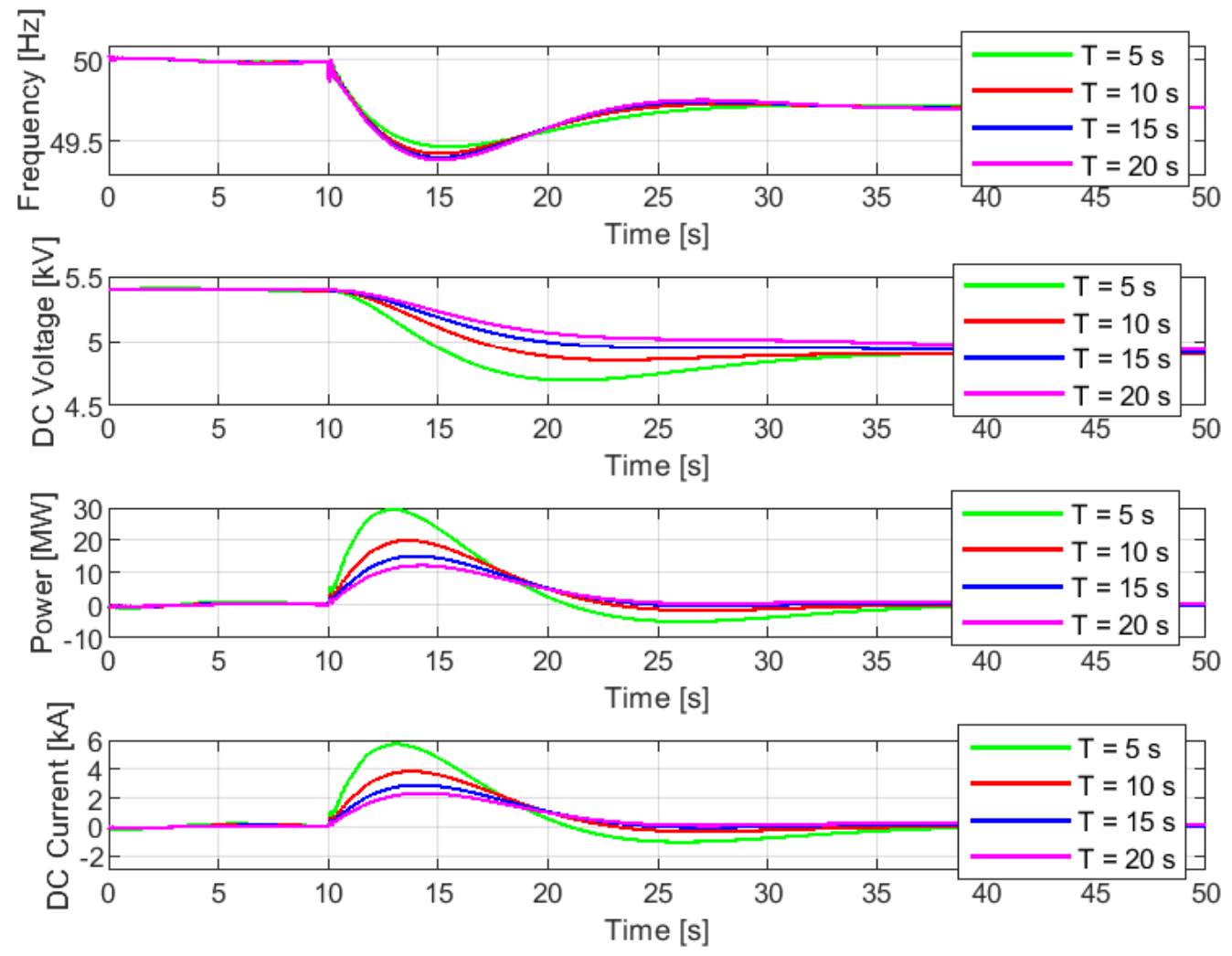

Figure 14. FFR provision from the converter-connected SC with varying time constants (from top to bottom: system frequency, SC terminal DC voltage, SC output DC power, SC output DC current).

Table 6. Overview of simulation results of FFR provision from the converter-connected SC in systems with varying time constants.

\begin{tabular}{ccccc}
\hline Parameters & $\boldsymbol{T}_{V f}=\mathbf{5 ~ \mathbf { ~ }}$ & $\boldsymbol{T}_{V f}=\mathbf{1 0} \mathbf{s}$ & $\boldsymbol{T}_{V f}=\mathbf{1 5} \mathbf{s}$ & $\boldsymbol{T}_{V f}=\mathbf{2 0 ~ \mathbf { ~ }}$ \\
\hline Frequency Nadir Improvement (Hz) & 0.14 & 0.10 & 0.07 & 0.06 \\
ROCOF Improvement (Hz/s) & 0.05 & 0.02 & 0.02 & 0.02 \\
Minimum SC Voltage (kV) & 4.70 & 4.85 & 4.91 & 4.94 \\
Maximum SC Power (MW) & 29.58 & 19.94 & 15.18 & 12.28 \\
Maximum SC Current (kA) & 5.74 & 3.83 & 2.90 & 2.33 \\
\hline
\end{tabular}

It could be concluded that smaller time constants improve the performance of droopbased FFR, including frequency nadir and average ROCOF, regardless of the SC integration methods. Similar to what has been concluded in the sensitivity analysis of droop coefficients, special attention needs to be paid to the selection of the directly connected capacitor if the low-pass filter is redesigned, since its time constant plays a role in capacitor size calculation as well.

\section{Conclusions}

The paper has developed fast frequency control strategies for the HWPP incorporating SC in the DC link of the WT for the provision of FFR, where droop-based FFR is implemented. Two topologies for integrating SC are considered: (1) direct connection to DC link and (2) connection to DC link through a DC-DC converter, and capacitor size calculation is discussed. The simulation results reveal that the proposed frequency control using SCs enhances the capabilities of HWPPs for providing FFR. The enhancement of FFR provision is even more noticeable under a system with lower inertia based on the study. According to a sensitivity analysis conducted in Section 5, droop coefficient and low-pass filter time constant both play a significant role in the performance of FFR provision. 
In terms of the comparison between directly connected SC and converter-connected SC, both topologies guarantee improvement on both ROCOF by at least $0.1 \mathrm{~Hz} / \mathrm{s}(5 \%$ compared to the base case) and frequency nadir by at least $0.05 \mathrm{~Hz}(10 \%$ compared to the base case), if the capacitor size is sufficient. However, for any given change on system inertia, droop coefficient and low-pass filter time constant, the size of the directly connected capacitor needs to be carefully selected to avoid low DC voltage that causes oscillations and malfunction of the grid side converter. Although the required capacitance for directly connected SC is generally larger than the converter-connected SC in order to guarantee the same performance, the preferred topology would eventually depend on the cost of DC-DC converters and additional capacitance. The detailed economic analysis will be covered in upcoming publications.

Author Contributions: Conceptualization, methodology, validation, visualization and writingoriginal draft preparation, Q.L. and A.C.; writing-review and editing, Q.L., A.C. and K.D.; supervision, project administration and funding acquisition, K.D. and P.S. All authors have read and agreed to the published version of the manuscript.

Funding: The work in this study is partly supported by the EUDP HybridStorage project.

Acknowledgments: The authors would like to thank Michel Maher Naguib Rezkalla from Ørsted for his support. Michel was with Vestas at the time of the work performed.

Conflicts of Interest: The authors declare no conflict of interest.

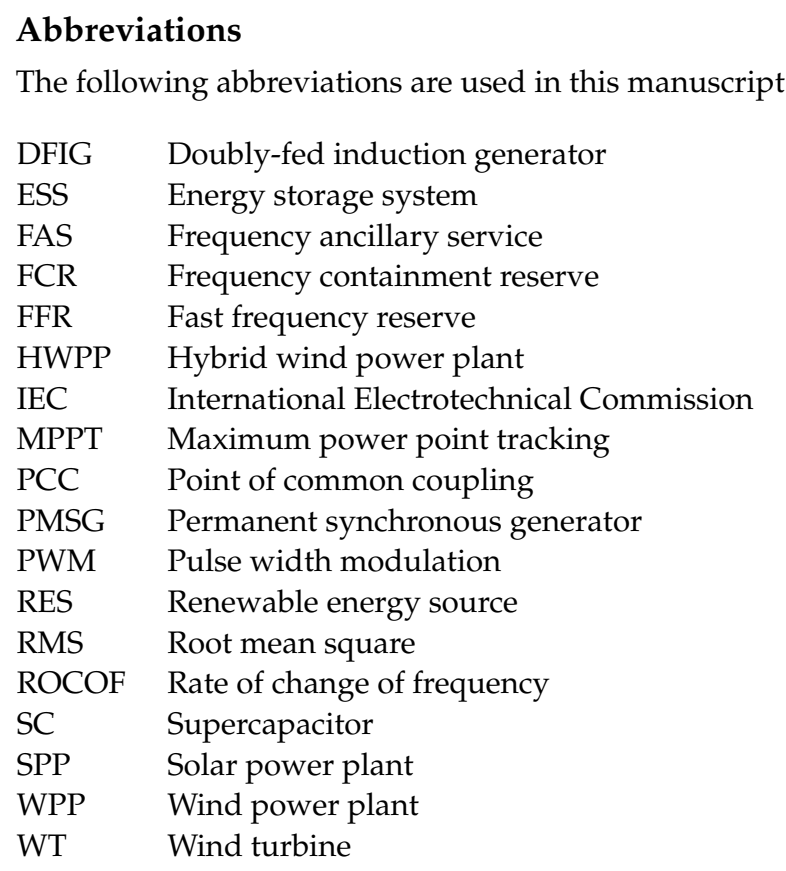

\section{Appendix A}

\section{Appendix A.1. Main Grid Data Configuration}

In this section, the utility grid model is presented with the main parameters of generators, loads, transformers and transmission lines. One thermal power plant G2b has been added to the original model, and maintains similar characteristics to thermal power plant 2. Furthermore, this additional power plant is also connected to Bus 2. Table A1 includes the data for all the generators and loads. Table A2 shows the data for all the transformers while the data for transmission lines is included in Table A3. 
Table A1. Generator and load data for the utility grid.

\begin{tabular}{ccccc}
\hline Power Plant & Units & Total Capacity (MVA) & Load & Active Power (MW) \\
\hline 1 (Thermal) & 6 & 752 & L01 & 300 \\
2 (Thermal) & 2 & 320 & L02 & 250 \\
2 b (Thermal) & 2 & 320 & L03 & 350 \\
3 (Thermal) & 2 & 384 & L04 & 300 \\
4 (Hydro) & 3 & 474 & L05 & 100 \\
& & & L06 & 150 \\
\hline
\end{tabular}

Table A2. Transformer data of the utility grid.

\begin{tabular}{ccccc}
\hline Transformer & Type & Capacity (MVA) & Uk(\%) & Connection Group \\
\hline T1 & Autotransformer & 500 & 13 & $Y_{n}-Y_{n}$ \\
T2 & Autotransformer & 500 & 13 & $Y_{n}-Y_{n}$ \\
Tg1 & Step-up & 800 & 12 & $Y_{n}-Y_{n}$ \\
Tg2 & Step-up & 350 & 12 & $Y_{n}-Y_{n}$ \\
Tg2b & Step-up & 350 & 12 & $Y_{n}-Y_{n}$ \\
Tg3 & Step-up & 250 & 10 & $Y_{n}-Y_{n}$ \\
Tg4 & Step-up & 400 & 11 & $Y_{n}-Y_{n}$ \\
\hline
\end{tabular}

Table A3. Transmission line data of the utility grid.

\begin{tabular}{cccccc}
\hline Line (Bus-Bus) & Length (km) & Voltage (kV) & $\mathbf{R}(\mathbf{O h m} / \mathbf{k m})$ & $\mathbf{X}(\mathbf{O h m} / \mathbf{k m})$ & $\mathbf{B}(\mathbf{u S} / \mathbf{k m})$ \\
\hline $1-2$ & 100 & 230 & 0.0598 & 0.476 & 3.474 \\
$1-6$ & 300 & 230 & 0.0598 & 0.476 & 3.474 \\
$2-5$ & 400 & 230 & 0.0598 & 0.476 & 3.474 \\
$3-4 \mathrm{a}$ & 100 & 230 & 0.0598 & 0.476 & 3.474 \\
$3-4 \mathrm{~b}$ & 100 & 230 & 0.0598 & 0.476 & 3.474 \\
$4-5$ & 150 & 230 & 0.0598 & 0.476 & 3.474 \\
$4-6$ & 300 & 230 & 0.0598 & 0.476 & 3.474 \\
$7-8$ & 600 & 345 & 0.0316 & 0.341 & 4.600 \\
\hline
\end{tabular}

\section{References}

1. UNFCCC. 2015. The Paris Agreement I UNFCCC. Available online: https://unfccc.int/sites/default/files/english_paris_ agreement.pdf (accessed on 9 June 2021).

2. European Parliament. Directive (EU) 2018/2001 of the European Parliament and of the Council on the Promotion of the Use of Energy from Renewable Sources. 2018. Available online: https://eur-lex.europa.eu/eli/dir/2018/2001/2018-12-21 (accessed on 9 June 2021).

3. Danish Ministry of Climate, Energy and Utilities. 2018. Energy Agreement. Available online: https://en.kefm.dk/Media/C/5/ Energy\%20Agreement\%202018\%20a-webtilgaengelig.pdf (accessed on 9 June 2021).

4. IEC. Wind Energy Generation Systems-Part 27-1: Electrical Simulation Models-Generic Models; IEC: Geneva, Switzerland, 2015.

5. Eriksson, R.; Modig, N.; Kuivaniemi, M. Ensuring Future Frequency Stability in the Nordic Synchronous Area. In Proceedings of the 18th International Wind Integration Workshop, Dublin, Ireland, 16-18 October 2019.

6. Das, K.; Hansen, A.D.; Koivisto, M.; Sørensen, P.E. Enhanced Features of Wind-Based Hybrid Power Plants. In Proceedings of the 4th International Hybrid Power Systems Workshop, Crete, Greece, 22-23 May 2019.

7. Ochoa, D.; Martinez, S. Fast-Frequency Response Provided by DFIG-Wind Turbines and its Impact on the Grid. IEEE Trans. Power Syst. 2017, 32, 4002-4011. [CrossRef]

8. Morren, J.; de Haan, S.W.; Kling, W.L.; Ferreira, J.A. Wind turbines emulating inertia and supporting primary frequency control. IEEE Trans. Power Syst. 2006, 21, 433-434. [CrossRef]

9. Hansen, A.D.; Altin, M.; Margaris, I.D.; Iov, F.; Tarnowski, G.C. Analysis of the short-term overproduction capability of variable speed wind turbines. Renew. Energy 2014, 68, 326-336. [CrossRef] 
10. Altin, M.; Kuhlmann, J.C.; Das, K.; Hansen, A.D. Optimization of synthetic inertial response from wind power plants. Energies 2018, 11, 1051, [CrossRef]

11. Altin, M.; Hansen, A.D.; Barlas, T.K.; Das, K.; Sakamuri, J.N. Optimization of Short-Term Overproduction Response of Variable Speed Wind Turbines. IEEE Trans. Sustain. Energy 2018, 9, 1732-1739. [CrossRef]

12. Zhu, J.; Hu, J.; Hung, W.; Wang, C.; Zhang, X.; Bu, S.; Li, Q.; Urdal, H.; Booth, C.D. Synthetic Inertia Control Strategy for Doubly Fed Induction Generator Wind Turbine Generators Using Lithium-Ion Supercapacitors. IEEE Trans. Energy Convers. 2018, 33, 773-783. [CrossRef]

13. Tan, Y.; Muttaqi, K.M.; Ciufo, P.; Meegahapola, L.; Guo, X.; Chen, B.; Chen, H. Enhanced Frequency Regulation Using Multilevel Energy Storage in Remote Area Power Supply Systems. IEEE Trans. Power Syst. 2019, 34, 163-170. [CrossRef]

14. Arani, M.F.M.; El-Saadany, E.F. Implementing Virtual Inertia in DFIG-Based Wind Power Generation. IEEE Trans. Power Syst. 2013, 28, 1373-1384. [CrossRef]

15. Adu, J.A.; Napolitano, F.; Nucci, C.A.; Diego Rios Penaloza, J.; Tossani, F. A DC-Link Voltage Control Strategy for Fast Frequency Response Support. In Proceedings of the 20th IEEE Mediterranean Electrotechnical Conference (MELECON), Palermo, Italy, 16-18 June 2020. [CrossRef]

16. Zeng, X.; Li, X.; Wang, S.; Liu, T.; Zhang, C.; Zhang, H. Virtual Inertia Control and Short-Term Primary Control for PMSG-Based Wind Turbine Using Supercapcitor. In Proceedings of the 4th International Conference on HVDC (HVDC), Xi'an, China, 6-9 November 2020. [CrossRef]

17. DIgSILENT. DIgSILENT PowerFactory-User Manual, Version 2019; DIgSILENT GmbH: Gomaringen, Germany; 2019.

18. Hansen, A.D.; Sørensen, P.; Iov, F.; Blaabjerg, F. Centralised power control of wind farm with doubly fed induction generators. Renew. Energy 2006, 31, 935-951. [CrossRef]

19. Adamczyk, A.; Altin, M.; Göksu, O.; Teodorescu, R.; Iov, F. Generic 12-bus test system for wind power integration studies. In Proceedings of the 15th European Conference on Power Electronics and Applications (EPE), Lille, France, 2-6 September 2013. 